\title{
Diagnosing idiopathic/cryptogenic epilepsy syndromes in infancy
}

\author{
N Sarisjulis, B Gamboni, P Plouin, A Kaminska, O Dulac
}

\begin{abstract}
Purpose-To determine the characteristics that permit diagnosis of the type of epilepsy beginning in the 1st year of life, and to determine from what age such characteristics are recognisable.

Patients-From 430 non-selected patients who began having seizures in the 1st year of life and were referred to the neuropaediatric department of Saint Vincent de Paul Hospital, those with epileptic spasms as the first seizure type, those with recognisable aetiology, and those for whom early history was not reliable were excluded.
\end{abstract}

Methods-For the remaining 140 patients, the age at which clinical and electroencephalogram (EEG) characteristics met those of recognisable epilepsy syndromes according to the ILAE classification was studied.

Results-In most epilepsy syndromes, the diagnosis could be made within three months of onset of the disorder. The most difficult was to distinguish cryptogenic localisation related epilepsy from severe myoclonic epilepsy in infancy. Repeat focal seizures and persisting spike focus were the earliest and most reliable signs of localisation related epilepsy, whereas alternating focal seizures, generalised myoclonus, and/or spike waves appeared before the end of the 1st year in most infants with severe myoclonic epilepsy. However, for 39 patients it was not possible to reach the diagnosis of a precise syndrome.

Conclusion-For over three quarters of infants with cryptogenic/idiopathic epilepsy, it is possible to reach a syndromic diagnosis within the first months of the disease, based on clinical and EEG characteristics. However, for one quarter, no diagnosis is possible based on the currently available classification.

(Arch Dis Child 2000;82:226-230)

Keywords: epilepsy; convulsions; diagnosis

Laboratoire de Neurophysiologie Clinique, Hôpital Saint

Vincent de Paul

P Plouin

INSERM U29, Hôpital Saint Vincent de Paul O Dulac

Correspondence to: Dr Dulac

Accepted 28 September 1999 remains a major issue for infantile spasms and is likely to have devastating consequences for cognition, diagnosis of this syndrome is not a than at any other stage of life. ${ }^{12}$ Hospital series report that infantile spasms and other kinds of epilepsy occur in similar proportions, ${ }^{3}$ with contrasts with the rare cases of benign convul- challenging problem, as long as spasms are the first type of seizure the infants exhibit. ${ }^{78}$ It is more difficult to identify the type of epilepsy in the group without infantile spasms, particularly when no aetiology can be identified from familial or personal history, clinical examination, neuroradiology, and biochemical or cytogenetic investigation.

Choice of antiepileptic drug treatment depends on the epilepsy syndrome, and there is growing evidence that inappropriate choices can lead to worsening of the epilepsy. ${ }^{9-12}$ In the 1 st year of life, a period when the child experiences very rapid maturation of motor and cognitive functions, such mischoices could have particularly devastating consequences on development.

In cases other than infantile spasms and in patients with no identifiable aetiology, early diagnosis remains difficult in many instances. For example, patients with severe myoclonic epilepsy do not exhibit myoclonus or spike wave activity until the 2nd or 3rd year of life. ${ }^{13}{ }^{14}$ Identifying localisation related (focal) epilepsy is also most difficult in the 1st year of life in the absence of any structural brain lesion disclosed by neuroradiology. ${ }^{15} 16$

Our study was undertaken to determine at what age, and based on which characteristics, the diagnosis of the various epilepsy syndromes can be achieved in infancy.

\section{Patients}

We identified from the database collected from 1986 to 1996 in our hospital department, all the files of patients who had experienced their first seizure within the 1st year of life, for whom no aetiology could be identified based on family or personal history, clinical examination, neuroradiology, and biochemical or cytogenetic investigation, for whom a precise description of seizures and electroencephalogram (EEG) tracings in the 1st year of life were available, and who were followed for at least two years from onset of the seizure disorder.

The dataset comprised 430 patients who had experienced their first seizure in the 1st year of life. Eighty two patients were excluded from the study because they had been seen long after the onset of the seizure disorder and precise characteristics regarding the beginning of the epilepsy, description of first seizures, or first EEG tracings were not available. Two hundred and eight of the remaining had either infantile spasms as the first seizure type or an identifiable cause for the epilepsy, and they were therefore also excluded from our study.

Thus, 140 patients met the entry criteria and their files were studied retrospectively. 
Table 1 Classification of the series of 140 patients with cryptogenic/idiopathic epilepsy starting in the 1st year of life and referred to Saint Vincent de Paul hospital from 1986 to 1996

\begin{tabular}{|c|c|c|}
\hline Diagnosis & $n$ & Reference \\
\hline \multicolumn{3}{|l|}{ ILAE included syndromes } \\
\hline Early infantile epileptic encephalopathy & 7 & Ohtahara et al ${ }^{18}$ \\
\hline Early myoclonic encephalopathy & 5 & Aicardi et $a l^{19}$ \\
\hline Idiopathic neonatal convulsions & 3 & Plouin et $a l^{20}$ \\
\hline Severe myoclonic epilepsy in infancy & 42 & Dravet et $a l^{13}$ \\
\hline $\begin{array}{l}\text { Cryptogenic localisation related epilepsy } \\
\text { (followed by infantile spasms) }\end{array}$ & $\begin{array}{l}32 \\
(9)\end{array}$ & Duchowny et al ${ }^{15}$ \\
\hline Benign myoclonic epilepsy in infancy & 6 & Dravet et $a l^{11}$ \\
\hline \multicolumn{3}{|l|}{ Non ILAE included syndromes } \\
\hline Migrating partial seizures in infancy & 4 & Coppola et al $l^{2}$ \\
\hline Benign non-familial infantile convulsions & 2 & Watanabe et al \\
\hline Unclassifiable cases & 39 & \\
\hline
\end{tabular}

Unclassifiable cases cephalopathy" (five patients) remained uncertain, mainly because of the difficulty identifying myoclonus in the neonatal period.

"Idiopathic neonatal convulsions" (three patients) were difficult to identify at onset, and although it was suspected during the acute period based on the clinical data and both ictal and interictal EEG characteristics, it is only with a follow up of at least one year that, with normal development, the diagnosis could be confirmed retrospectively.

We could not determine the proper diagnosis of one additional patient who, from the neonatal period and for three months, exhibited a variant of hypsarrhythmia without developing any spasms.

\section{Methods}

For each patient, clinical and neurophysiological characteristics were studied retrospectively at onset and during the course of the disease. We reviewed the previous history, including the familial antecedents. Special emphasis was given to the age of occurrence and characteristics of first seizures, and at what age there was a change in the type of seizures or a new type if this occurred, as well as EEG features during follow up. In our department, patients with frequent seizures systematically undergo video/ polygraphic recording, including electromyography of affected muscles. We then determined at what age the type of epilepsy syndrome could be identified and which clinical and EEG characteristics permitted such diagnosis.

\section{Results}

OVERALL DESCRIPTION OF THE SERIES

A precise type of epilepsy could be identified in 103 patients $(72.5 \%), 97$ of whom met the diagnostic criteria for epilepsy syndromes included in the 1989 ILAE classification, ${ }^{17}$ whereas the remaining six had the characteristics of syndromes identified more recently (table 1).

\section{SYNDROMIC DIAGNOSIS}

Conditions of diagnosis varied according to the age of occurrence of the first seizure.

\section{In the neonatal period}

Three syndromes were identified in 15 neonates. "Epileptic encephalopathies with suppression bursts" (12 patients) were recognised from the neonatal period, based on the EEG, once any responsibility of antiepileptic drugs could be excluded. Because the absence of brain malformation on neuroradiology was a selection criterion, the distinction between "early infantile epileptic encephalopathy" (seven patients) and "neonatal epileptic en-

Table 2 Benign myoclonic epilepsy of infancy. Ages of first seizure, characteristic electroencephalogram (EEG), diagnosis, and last seizure

\begin{tabular}{lcccl}
\hline Patient & $\begin{array}{l}\text { First seizure } \\
\text { (months) }\end{array}$ & $\begin{array}{l}\text { EEG characteristics } \\
\text { (months) }\end{array}$ & $\begin{array}{l}\text { Diagnosis } \\
\text { (months) }\end{array}$ & $\begin{array}{l}\text { Last seizure } \\
\text { (months) }\end{array}$ \\
\hline 1 & 8 & 8 & 8 & 17 \\
2 & 6 & 6 & 6 & 12 \\
3 & 4 & 8 & 8 & 10 \\
4 & 8 & 9 & 9 & 10 \\
5 & 9 & 10 & 10 & 36 \\
6 & 10 & 12 & 12 & 16 \\
\hline
\end{tabular}

\section{In infancy}

Diagnosis of "benign non-familial infantile convulsions" (two patients) was based on the characteristics of seizures without evidence of any triggering feature and with normal interictal EEG. As in the neonatal period, it needed several months' follow up and full recovery to confirm the diagnosis retrospectively.

The diagnosis of "benign myoclonic epilepsy of infancy" (six cases) was done 0-5 months (mean, 1.1) after the onset of the disorder, based on the ictal video polygraphic, including electromyography, recording. However, for year of life, the only ones considered in our study, cessation of seizures and follow up of developmental milestones into the 2 nd year of life were necessary to confirm the benign nature of the condition (table 2) and cognitive recovery.

Recognising "migrating partial seizures of infancy" (four patients) was difficult at onset. High seizure frequency was the main characteristic, but diagnosis only became possible after the end of the first 3 months of life, when periods of very frequent seizures culminated in continuous and migrating partial seizures amenable to ictal EEG recording.

The most difficult was to distinguish at onset "cryptogenic localisation related epilepsy" from "severe myoclonic epilepsy in infancy". In both instances there were partial motor seizures and no neuroradiological anomalies at the beginning of the disorder. Cryptogenic localisation related epilepsy (32 patients) began between day 1 and 10 months of age (mean, 4.3 months) (table 3). Clinical manifestations suggestive of a focal discharge could be recognised from day 1 to 13 months of age, and from then on the seizures remained of a single seizure type. The EEG showed persistent focal spikes before the age of 12 months in 27 of the 32 patients. Time lag from first seizure to the first recording of focal spikes ranged from 0 to 27 months (mean, 2.6), with 17 patients having less than one month, and only eight patients with more than three months lag. In nine patients, ictal EEG recording permitted the diagnosis of localisation related epilepsy within one month of the onset of seizures, before focal features could be drawn from clinical observation. Severe myoclonic epilepsy in infancy (42 patients) started infants who had their first seizures in the 1 st 
Table 3 Cryptogenic localisation related epilepsy. Age of appearance of the characteristics, age at diagnosis, and time lag from first seizure to diagnosis

\begin{tabular}{|c|c|c|c|c|c|c|}
\hline Patient & $\begin{array}{l}\text { First } \\
\text { seizure }\end{array}$ & $\begin{array}{l}\text { Single type focal } \\
\text { seizures }\end{array}$ & $\begin{array}{l}E E G \\
\text { (ictal) }\end{array}$ & $\begin{array}{l}E E G \\
\text { (focal) }\end{array}$ & Diagnosis & Time lag \\
\hline 1 & 6 & 6 & NR & 15 & 15 & 9 \\
\hline 2 & 3 & 4 & 4 & 4 & 4 & 1 \\
\hline 3 & 7 & 12 & 12 & 12 & 12 & 5 \\
\hline 4 & 8 & 8 & 8 & 8 & 8 & 0 \\
\hline 5 & 3 & 3 & NR & 4 & 4 & 1 \\
\hline 6 & 2.5 & 2.5 & NR & 2.5 & 2.5 & 0 \\
\hline 7 & 5 & 10 & NR & - & 10 & 5 \\
\hline 8 & 10 & 10 & 10 & 10 & 10 & 0 \\
\hline 9 & Day 2 & 2 & 4 & 2 & 2 & 2 \\
\hline 10 & 8 & 8 & NR & 8 & 8 & 0 \\
\hline 11 & 9 & 9 & 17 & 17 & 17 & 8 \\
\hline 12 & 5.5 & 6 & NR & 6 & 6 & 0.5 \\
\hline 13 & 1 & 1 & NR & 10 & 10 & 9 \\
\hline 14 & 5 & 17 & NR & 32 & 17 & 12 \\
\hline 15 & 9 & 9 & NR & 9 & 9 & 0 \\
\hline 16 & 5 & 5 & 6 & 6 & 6 & 1 \\
\hline 17 & 10 & 13 & 10 & 10 & 10 & 0 \\
\hline 18 & 3 & 3 & NR & 8 & 8 & 5 \\
\hline 19 & 9 & 10 & 12 & 11 & 11 & 2 \\
\hline 20 & 5 & 5 & NR & 5 & 5 & 0 \\
\hline 21 & 1 & 1 & 1 & 1 & 1 & 0 \\
\hline 22 & 2.5 & 3 & NR & 3 & 3 & 0.5 \\
\hline 23 & 7 & 7 & NR & 7 & 7 & 0 \\
\hline 24 & 3 & 3 & 4 & 4 & 4 & 1 \\
\hline 25 & Day 1 & 1.5 & 1.5 & Day 1 & 1.5 & 1.5 \\
\hline 26 & Day 15 & Day 15 & NR & Day 16 & 0.5 & 0 \\
\hline 27 & 4.5 & 5 & 11 & 5 & 5 & 0.5 \\
\hline 28 & 1 & 1 & NR & 1 & 1 & 0 \\
\hline 29 & Day 4 & 1 & 1 & 1 & 1 & 0.8 \\
\hline 30 & 3 & 3 & 3 & 3 & 3 & 0 \\
\hline 31 & 2 & 7 & 7 & 3.5 & 3.5 & 1.5 \\
\hline 32 & 1.5 & 3 & NR & 5 & 5 & 3.5 \\
\hline
\end{tabular}

Unless specified otherwise, ages and time lags are given in months. NR, not recorded.

between 1 and 9 months of age (mean, 5), the first non-febrile seizure occurring between 2 and 20 months (mean, 7.6). The syndrome was recognised between 3 and 24 months of age (mean, 8.6) based on the combination of febrile and non-febrile convulsive seizures with one of the three following characteristics: myoclonic seizures, focal seizures affecting alternately both sides of the body, or generalised spike wave discharges (fig 1). For 37 patients, this combination was reached before the age of 1 year, for 40 it was reached before the age of 18 months, and for only one (patient 10 ) it was delayed until later than the end of the 2 nd year of life. In five patients, the EEG showed some focal spikes on one EEG recording, between 4

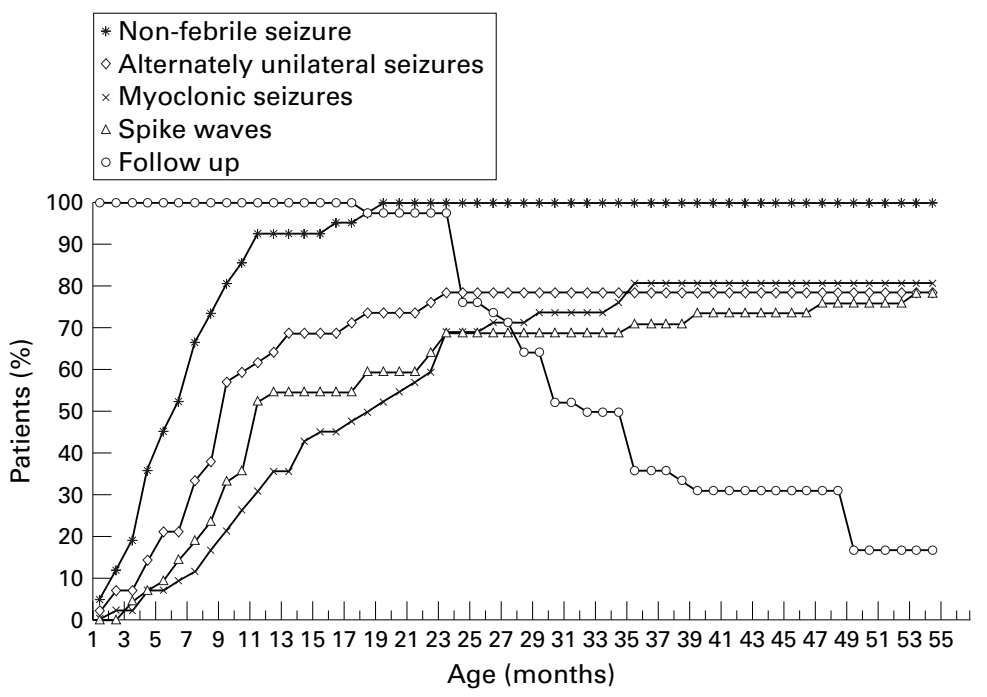

Figure 1 Severe monoclonic epilepsy in infancy: cumulative age of onset of various forms. and 10 months of age, but the next recording did not confirm this finding, and later EEGs showed either no spikes or generalised discharges.

However, in 39 patients $(27.5 \%)$, no definite syndromic diagnosis could be made at the end of follow up that ranged from 24 to 84 (mean, 45.3) months of age. No history, neuroradiological, cytogenetic, or biochemical investigation could disclose the aetiology. It was not even possible to determine which cases were likely to be related to some inborn error of metabolism not identified to date, because the condition was progressively worsening without any clue as to whether the seizures alone could account for the worsening, or whether it was caused by the underlying disease itself.

\section{Discussion}

Our study shows that when epilepsy begins in the 1 st year of life with seizures other than epileptic spasms, and without any evidence of structural brain damage, it is possible to recognise the epilepsy syndrome in a large proportion of cases. We found this to be possible according to the 1989 ILAE classification ${ }^{17}$ for $68 \%$ of the patients, and for $72 \%$ when including more recently identified syndromes. The syndrome could be recognised within a few months in over three quarters of these identifiable cases, based on seizure types and interictal EEG.

Although our series has no epidemiological value, figures are more likely to overestimate than to underestimate the incidence of unclassifiable cases in the general population, because the patients were drawn from a tertiary reference centre. Nevertheless, it shows that a sizeable number of patients are left with neither a precise aetiology nor syndromic diagnosis. Thus, it is likely that new syndromes or diseases producing epilepsy in the 1 st year of life await identification.

We should point out that discovering a brain lesion or inborn error of metabolism does not prevent identification of the epilepsy syndrome based on seizure type and interictal EEG for therapeutic purposes. Indeed, a focal lesion for instance might generate either localisation related epilepsy or infantile spasms, and determining the type of epilepsy helps in choosing the appropriate medication.

It was surprising to find that the proper diagnosis was possible for most patients before the end of the 1st year of life. For epilepsies beginning in the neonatal period, the longest time lag was for patients with benign convulsions, because a sufficient follow up was needed to evaluate psychomotor development. For epileptic encephalopathies beginning in the neonatal period, the distinction between myoclonic encephalopathy and early epileptic encephalopathy was often difficult and needed seizure video/polygraphic recording in addition to the interictal EEG pattern, but this could be done within one or two months.

As in the neonatal period, for epilepsies beginning in infancy, the diagnosis of benign convulsions needed at least two years' follow up, with the patient being seizure free. This also 
applies to benign myoclonic epilepsy of infancy, ${ }^{23}$ for which the disappearance of seizures and over two years' follow up of cognitive function are necessary to confirm the diagnosis. Thus, for the most benign cases beginning in the neonatal period or in infancy, a sufficient follow up is needed to establish good outcome, in contrast to epilepsies beginning in childhood, for which the combination of seizure type(s) together with interictal, clinical, and EEG characteristics usually allow the confident suggestion of a good prognosis. However, the delay in making the diagnosis for infants does not affect treatment choices.

Regarding more severe cases beginning in infancy, one syndrome-migrating partial seizures of infancy-produces very frequent seizures, which can be recorded in virtually all cases, enabling the correct diagnosis to be made. The ictal recording shows frequent, migrating, partial seizures affecting both hemispheres and can be done within the first three months of the seizure disorder.

The most difficult and the most important in terms of therapeutic impact concerns the distinction between cryptogenic localisation related epilepsy and severe myoclonic epilepsy of infancy. But here again, the distinction could be made quite early in life, and a simple therapeutic algorithm should be drawn from these findings. In cryptogenic localisation related epilepsy, clinical characteristics of seizures that demonstrate their focal origin might be lacking for the first few months of the disorder. ${ }^{16}$ However, they were recognised as focal seizures before the end of the 1st year of life in 30 of the 32 cases, and from the very first month of the disorder in 24 cases. Focal spikes persisting on repeat EEG recordings could be observed in half the cases less than one month after the first seizures, and this was the case in three patients even before clinical ictal focal features became apparent. In some patients, seizures are so frequent from the first weeks of the disorder that they can be recorded. In three of nine such patients in our series, prolonged video/ polygraphy permitted recording of seizures, which contributed mostly to the diagnosis by showing that there was a single focus, thus establishing the diagnosis of localisation related epilepsy. Focal features that had not been identified clinically were recognised on the recording. Therefore, it is most important to make all possible efforts to record for several hours patients who have daily seizures and for whom the proper diagnosis has not yet been established. To improve the possibilities of ictal recording, we use a mobile video-EEG recording system, which permits 24 hour recording for any patient in an emergency, as soon as he or she enters the ward.

In severe myoclonic epilepsy of infancy, the full pattern of the syndrome was considered to have been reached when the previously normal patient had exhibited a combination of repeat febrile and non-febrile convulsions with at least one of the following features: alternating unilateral seizures, massive myoclonus, or generalised spike waves. Thus, the occurrence of myoclonus was not considered as a necessary feature to establish the diagnosis, because in some cases myoclonus can remain quite rare or be delayed until the 4 th year of life. ${ }^{14}$ In addition, cases with the same age of onset, and various seizure types but without myoclonus, have been reported to exhibit an outcome very similar to that of severe myoclonic epilepsy of infancy. ${ }^{14}{ }^{24}$ The combination of febrile and non-febrile convulsions with alternating unilateral seizures and/or generalized spike waves was present before the end of the 1st year of life in $88 \%$ of the patients ultimately diagnosed as having severe myoclonic epilepsy of infancy. The occurrence of focal spikes on interictal EEG recordings performed in the middle of the 1 st year of life, as seen in four cases, should not mislead. It was transient and did not persist on repeat recordings in our series. Additional clues to the difficult diagnosis of severe myoclonic epilepsy of infancy consist of the occurrence of seizures triggered by fever, and of long lasting seizures. ${ }^{13}$ On the other hand, focal motor seizures at the beginning of the disorder are very likely to suggest localisation related epilepsy. However, when repeat seizures are considered, they affect different parts of the body in different seizures.

Therapeutic conclusions can be drawn from these findings. Localisation related epilepsy can be greatly improved by various drugs, including valproate, ${ }^{25}$ benzodiazepines, ${ }^{26}{ }^{27}$ and lamotrigine, ${ }^{12}$ and to our knowledge, there has been no consistent observation of aggravation of localisation related epilepsy in infancy as a result of inappropriate drug choices. In contrast, several drugs are likely to worsen severe myoclonic epilepsy of infancy in a sizeable proportion of patients. Such an effect has been reported for carbamazepine, ${ }^{9}$ and vigabatrin, ${ }^{11}$ and with lamotrigine in up to $80 \%$ of cases. ${ }^{10}$ Occasionally, worsening can consist of the occurrence of status epilepticus.

Based on our findings, it seems reasonable to advise the use of valproate as first drug, not only for infants with generalised convulsive febrile or non-febrile seizures, but also for those with focal seizures before the correct diagnosis of localisation related epilepsy can be established. In intractable cases, clobazam could be added, rather than clonazepam, which can occasionally be poorly tolerated in combination with valproate. ${ }^{28} 29$

As soon as the correct diagnosis has been recognised, it is possible to advise on an appropriate treatment, including carbamazepine, vigabatrin, or lamotrigine for cryptogenic localisation related epilepsy.

\section{Conclusion}

In conclusion, for most epilepsy syndromes beginning in infancy, the syndromic diagnosis can be reached within a few months of onset, particularly for those patients in whom seizures remain uncontrolled. The most difficult problem is distinguishing between severe myoclonic epilepsy and cryptogenic localisation related epilepsy. A special effort should be made to record seizures when they occur at a high frequency. Therefore, from the therapeutic point of view, it seems reasonable to start with 
valproate until a firm diagnosis can be made. This choice is suggested to avoid the risk of increasing seizures with drugs known to worsen severe myoclonic epilepsy in infancy, namely carbamazepine, vigabatrin, or lamotrigine, all of which may be useful in localisation related epilepsy. It is only when the diagnosis of cryptogenic localisation related epilepsy is clearly established that these drugs can be advised.

1 Hauser W, Kurland LT. The epidemiology of epilepsy in Rochester Minnesota, 1935 through 1969. Epilepsia 1975;16:1-66.

2 Luna D, Chiron C, Pajot N, Dulac O, Jallon P. Epidémiologie des épilepsies de l'enfant dans le département de L'Oise (France). In: Epidémiologie des épilepsies. Paris: John Libbey, 1988:41-53.

3 Chevrie JJ, Aicardi J. Convulsive disorders in the first year of life: etiologic factors. Epilepsia 1977;18:489-98.

4 Chevrie JJ, Aicardi J. Convulsive disorders in the first year of life: neurologic and mental outcome and mortality. Epileplife: neurologic and
sia $1978 ; 19: 67-74$.

5 Watanabe K. Benign partial epilepsies. In: Wallace S, ed. Epilepsy in children. London: Chapman and Hall, 1996 293-313.

6 Vigevano F, Fusco L, Di Capua M, Ricci S, Sebastianelli R, Lucchini P. Benign infantile familial convulsions. Eur $\mathcal{F}$ Pediatr 1992;151:608-12

7 Villeneuve N, Soufflet C, Plouin P, et al. Traitement des spasmes infantiles par vigabatrin en première intention et en monothérapie: à propos de 70 nourrissons. Arch Pediat 1998;5:731-8.

8 Dulac O, Chugani HT, Dalla Bernardina B, eds. Infantile spasm and West syndrome. London: WB Saunders.

9 Perucca E, Gram L, Avanzini G, Dulac O. Antiepileptics drugs as a cause of worsening seizures. Epilepsia 1998;39:517.

10 Guerrini R, Dravet C, Genton P, et al. Lamotrigine and seizure aggravation in severe myoclonic epilepsy. Epilepsia zure aggravation

11 Lortie A, Chiron C, Mumford J, Dulac O. The potential for increasing seizure frequency, relapse, and appearance of new seizure types with vigabatrin. Neurology 1993;43:S247.

12 Schlumberger E, Chavez F, Palacios L, et al. Lamotrigine in treatment of 120 children with epilepsy. Epilepsia 1994;35 359-67.

13 Dravet Ch, Bureau M, Guerrini R, Giraud N, Roger J. Severe myoclonic epilepsy in infancy. In: Roger J, Bureau M, Dravet Ch, Dreifuss FE, Perret A, Wolf P, eds. Epileptic syndromes in infancy, childhood and adolescence. London: John Libbey, 1992:75-88.
14 Yakoub M, Dulac O, Jambaque I, Plouin P. Early diagnosis of severe myoclonic epilepsy in infancy. Brain Dev 1992;14: 299-303.

15 Duchowny MS. Complex partial seizures of infancy. Arch Neurol 1987;44:911-14.

16 Luna D, Plouin P, Dulac O. Semiology of cryptogenic partial seizures in infancy. Electroencephalogr Clin Neurophysiol 1988;70:9-16.

17 Proposal for revised classification of epilepsies and epileptic syndromes. Epilepsia 1989;30:389-99.

18 Ohtahara S, Ohtsuka Y, Yamatogi Y,Oka E, Inoue H. Early epileptic encephalopathy with suppression-bursts. In: Roger J, Bureau M, Dravet Ch, Dreifuss FE, Perret A, Wolf $\mathrm{P}$, eds. Epileptic syndromes in infancy, childhood and adolescence. London: John Libbey, 1992:25-34.

19 Aicardi J. Early myoclonic encephalopthy (neonatal myoclonic encephalopathy). In: Roger J, Bureau M, Dravet Ch, Dreifuss FE, Perret A, Wolf P, eds. Epileptic syndromes in infancy, childhood and adolescence. London: John Libbey, 1992:13-23.

20 Plouin P. Benign idiopathic neonatal convulsions (familial and non-familial). In: Roger J, Bureau M, Dravet Ch, Dreifuss FE, Perret A, Wolf P, eds. Epileptic syndromes in infancy, childhood and adolescence. London: John Libbey, 1992:3-11.

21 Dravet Ch, Bureau M, Roger J. Benign myoclonic epilepsy in infancy. In: Roger J, Bureau M, Dravet Ch, Dreifuss FE, Perret A, Wolf $\mathrm{P}$, eds. Epileptic syndromes in infancy, childhood and adolescence. London: John Libbey, 1992:6774.

22 Coppola G, Plouin P, Chiron C, Robain O, Dulac O. Migrating partial seizures in infancy: a malignant disorder with developmental arrest. Epilepsia 1995;36:1017-24.

23 Lombroso CT. Early myoclonic encephalopathy, and benign and severe infantile myoclonic epilepsies: a critical review and personal contributions. F Clin Neurophysiol 1990;77: 380-408.

24 Ogino T, Ohtsuka Y, Yamatogi Y, Oka E, Ohtahara S. The epileptic syndrome sharing common characteristics during early childhood with severe myoclonic epilepsy in infancy. Ipn F Psychiatry Neurol 1989;43:479-81.

25 Verity CM, Hosking G, Easter DJ. A multicentre comparative trial of sodium valproate and carbamazepine in paediatric epilepsy. The paediatric EPITEG collaborative group. Dev Med Child Neurol 1995;37:97-108.

26 Farrell K. Benzodiazepines in the treatment of children with epilepsy. Epilepsia 1986;27(suppl 1):S45-51.

27 Dulac O, Figueroa D, Rey E, Arthus M. Monothérapie par le clobazam dans les épilepsies de l'enfant. La Presse Médicale 1983;12:1067-9.

28 Jeavons PM, Clark JE, Maheswari MC. Treatment of generalized epilepsies of childhood with sodium valproate (epilim). Dev Med Child Neurol 1977;19:9-25.

29 Schmidt D, Rhode M, Wolf P, Roeder-Wanner V. Tolerance to the antiepileptic drug. New York: Raven Press, 1986:109-15. 